\section{'AC Haroblush' Apricot}

\author{
Richard E.C. Layne ${ }^{1}$ and David M. Hunter ${ }^{2}$ \\ Agriculture and Agri-Food Canada, Harrow, Ontario NOR 1G0, Canada
}

Additional index words. Prunus armeniaca, fruit breeding, cold hardiness, disease resistance

'ACHaroblush' apricot (Prunus armeniaca L.), is a mid-season fresh market apricot released in 2000. This flavorful, attractive, medium-size apricot is productive, cold hardy, disease resistant, and suitable for the Ontario fresh market and commercial shipping. 'AC Haroblush' was tested as HW441 by members of the former Western Ontario Fruit Testing Association [WOFTA, now the Ontario Fruit Testing Association (OFTA)] and by members of the former New York State Fruit Testing Cooperative Association (NYSFTCA), and it appears to be adapted to regions where 'Goldcot' and 'Veecot' are successfully grown. This new cultivar, developed by Agriculture and Agri-Food Canada at Harrow, Ontario, Canada (AAFC-Harrow), is recommended by the Ontario Tender Fruit Producers' Marketing Board (OTFPMB) for trial planting in Ontario. 'AC Haroblush' has also been tested in the Rhône Valley, France, by Star Fruits. 'AC Haroblush', together with 'ACHarojoy' (Layne and Hunter, 2003a) and 'AC Harostar' (Layne and Hunter, 2003b), are the latest introductions from the AAFC apricot breeding program formerly located at Harrow.

\section{Origin}

'AC Haroblush' resulted from a controlled cross made in 1978 by R.E.C. Layne at AAFCHarrow between 'Harglow' (Layne, 1984) X 'Harcot' (Layne, 1978) (Fig. 1). Selected in 1984, 'ACHaroblush'was propagated on 'Haggith' apricot seedling rootstock (Layne and Harrison, 1975) beginning in 1984. Trees of 'AC Haroblush'/Haggith were placed in evaluation orchards at AAFC-Harrow in 1986. Between 1988 and 1995, 'AC Haroblush' was compared with 'Veecot', 'AC Harostar', and 'Harogem' which ripen within a few days of each other in the mid-season. Trees were propagated in cooperation with WOFTA under the designation HW441, and placed in regional trials with WOFTA members beginning in 1986 and with members of NYSFTCA beginning in 1993. 'AC Haroblush' is genetically stable and uniform.

Received for publication 2 Jan. 2002. Accepted for publication 19 May 2002. We thank H.O. Jackson, F.D. Stroud, E.W. Lamoure, M.D. St. Pierre, M.F. Gadsby, and D.B. Jessop for excellent technical assistance. We appreciate the assistance of the Western Ontario Fruit Testing Association and its growermembers in field performance evaluations.

${ }^{1}$ Retired.

${ }^{2}$ To whom reprint requests should be addressed. Present address: Univ. of Guelph, Dept. of Plant Agriculture, 4890 Victoria Ave. North, P.O. Box 7000, Vineland Station, Ontario L0R 2E0, Canada. E-mail: dhunter@uoguelph.ca

\section{Description}

Trees of 'AC Haroblush' are vigorous and semi-erect. Young shoots have strong anthocyanin coloration on the tips. One-year-old shoots are of medium vigor with very few laterals, and a medium number of conspicuous lenticels. Leaves are large and medium green on the upper surface. The shape of the leaf base is truncate, the leaf tip is acuminate, and the angle of the tip is broadly acute. The leaf margin is biserrate and undulation of the margin is slight. In a sample of 30 leaves taken from the mid-point of 30 randomly selected shoots in mid-summer of 1995, leaf blades were 83.4 $\pm 8.2 \mathrm{~mm}$ long and $71.7 \pm 7.1 \mathrm{~mm}$ wide, and leaf petioles were $33.5 \pm 4.5 \mathrm{~mm}$ long and 1.7 $\pm 0.2 \mathrm{~mm}$ thick. There is strong anthocyanin coloration of the upper surface of the petiole, weak anthocyanin coloration of the lower surface, and typically two to three medium-sized, globose, petiolar glands.

Flower buds are borne predominantly on short spurs. Flower bud density is high. Flowers are small, with pink circular petals with a short claw at the base. When flowers are fully open, the stigma is at the same level as the anthers. medium size, oblong, and asymmetric along the suture. The pedicel cavity is of medium depth, and the tip of the fruit is rounded. On tree-ripe fruits, fuzz is inconspicuous and sparse, and the skin surface appears smooth to the naked eye. The ground color of tree-ripe fruits is orange and a solid dark red blush covers $\approx 50 \%$ of the 30 firm ripe fruits, the fruit length was $51.1 \pm$ $2.4 \mathrm{~mm}$, the cheek width was $45.6 \pm 2.0 \mathrm{~mm}$, and the thickness across the suture was 44.3

Fig. 1. Pedigree of 'AC Haroblush' apricot.
Fruits of 'AC Haroblush' (Fig. 2) are of fruit surface. In 1995, in a random sample of

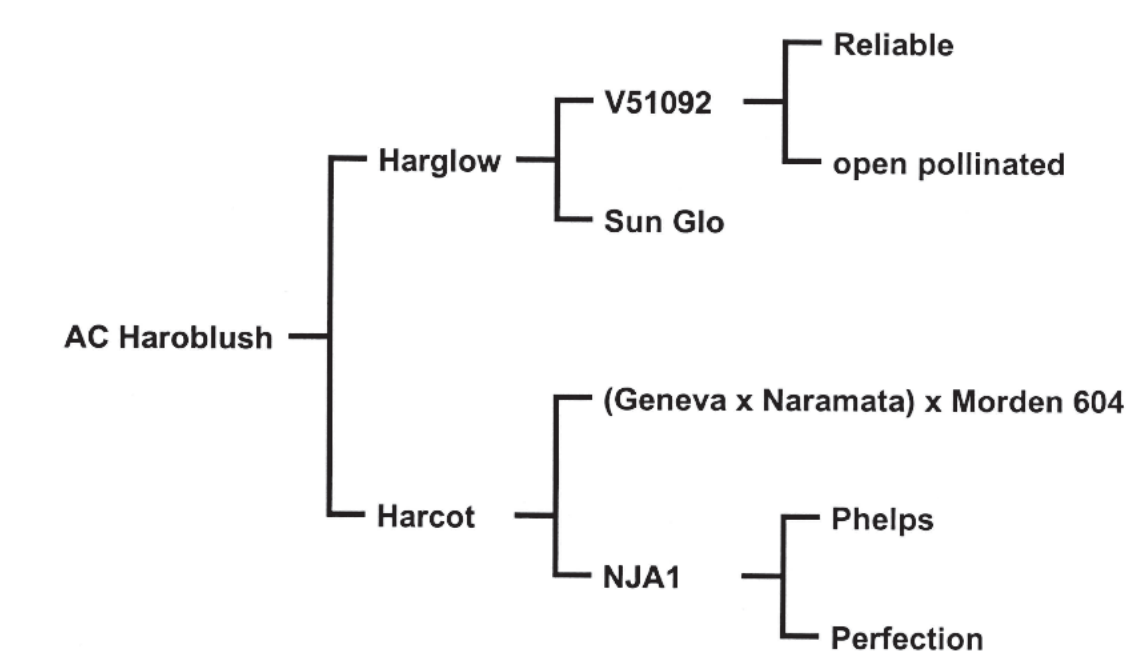

$\pm 2.5 \mathrm{~mm}$. Fruit weight was $53.8 \pm 7.4 \mathrm{~g}$, and $5.6 \% \pm 0.6 \%$ of that weight was attributed to the stone. The flesh is medium-orange in color, firm, fine-grained, sweet, and juicy. Fruit flavor is rated good to very good, depending on the season. The flesh does not adhere to the pit, which is small, plump, oblong, tan in color when dry, and has small wings and a keel. The kernels are plump and bitter, unlike 'AC Harojoy', which has sweet edible kernels.

\section{Performance}

In a replicated orchard planted at AAFCHarrow, 'AC Haroblush' was compared from 1988 to 1995 with 'Veecot', 'AC Harostar', and 'Harogem', all of which ripen within a few days of each other (Table 1). 'AC Haroblush' with 'Veecot' and 'Harogem' ranked first for tree vigor. 'AC Haroblush' ranked first for winter hardiness. 'AC Haroblush' was more resistant to perennial canker (Leucostoma sp.) and bacterial fruit spot [caused by Xanthomonas campestris pv. pruni (Smith) Dye], and was equally as resistant as the other three cultivars to bacterial leaf spot (also caused by $X$. campestris pv. pruni). Productivity was equal to 'Harogem' and superior to 'Veecot' and 'AC Harostar'. Ripening uniformity was equal to 'AC Harostar' and superior to 'Veecot' and 'Harogem'. Fruit size was equal to 'AC Harostar' and 'Harogem' and greater than 'Veecot'. Fruits of 'AC Haroblush', 'Veecot', and 'AC Harostar' were equally attractive but less attractive than 'Harogem'. Fruit blush was equal to 'Harogem' and more extensive than for 'Veecot' and 'AC Harostar'. Flesh of 'AC Haroblush' was softer than the other three cultivars. For all four cultivars, fruit flesh did not adhere to the pit. Flavor of 'AC Haroblush' was rated superior to 'Veecot' and equal to 'AC Harostar' and 'Harogem'. Overall performance for the 13 rated characteristics resulted in 'AC Haroblush' having the highest score followed, in descending order, by 'Harogem', 'AC Harostar', and 'Veecot'. The picking dates of these four cultivars will overlap to some extent, 'Veecot' being the first to ripen, followed by 'AC Haroblush', 'AC Harostar', and 'Harogem'. 'ACHaroblush' did 
not exhibit any serious faults that would hamper its commercial acceptance in Ontario. Skin cracking and brown rot [Monilinia fructicola (Wint.) Honey] were observed only in 1992, an unusually wet growing season, and even then, the incidence level was low. Preharvest drop was not a problem in any of the 8 years of testing.

Raw product tests carried out in 1995 with pulp of 'AC Haroblush' showed that soluble solids content was $12.6^{\circ} \mathrm{Brix}$, pH was 3.59 , and titratable acidity (\% citric) was 1.19; corresponding values for 'Veecot', the laboratory standard, were $11.7^{\circ} \mathrm{Brix}, \mathrm{pH} 3.53$, and titratable acidity 1.32 .

In 1990, ripened fruits of 10 cultivars and advanced test selections (including 'AC Haroblush') were processed as canned halves in $40 \%$ (w/v) syrup and as puree with $20 \%$ (w/w) granulated sugar. In masked identity taste panels, four trained panelists ranked canned halves of 'AC Haroblush' ninth, with a fair rating for color, poor to fair rating for the integrity of the pit cavity, fair rating for clarity of syrup, fair to good rating for flavor, and a poor rating for texture. Although the overall rating for the processed puree was fair to good, 'AC Haroblush' again ranked ninth, and was inferior to both 'Veecot' and 'Goldcot', which were used as reference standards. Thus, 'AC Haroblush' is not considered suitable for home processing.

Controlled freezing tests carried out on dormant, fully acclimated shoots of 'AC Haroblush' using a standard protocol (Layne and Gadsby, 1995) showed that in 4 of the 6 years, 'AC Haroblush' was as bud hardy as 'Goldcot'. The 6-year (1989-94) average $\mathrm{T}_{50}$ for flower buds of 'AC Haroblush' was $-27.7^{\circ} \mathrm{C}$, while the average for 'Goldcot' was $-29.4^{\circ} \mathrm{C}$. Wood hardiness of 'AC Haroblush' was equal to 'Goldcot' in 5 of the 6 years and was less hardy than 'Goldcot' in only 1 year. The 6-year average $\mathrm{T}_{50}$ for shoot xylem was $-34.6^{\circ} \mathrm{C}$ for ' $\mathrm{AC}$ Haroblush', and $-35.3^{\circ} \mathrm{C}$ for 'Goldcot'. Layne and Gadsby (1995) reported that 'AC Haroblush' was in the same hardiness class as 'Goldcot' for both flower buds $\left(\mathrm{T}_{50}\right.$ of $\left.-27.8{ }^{\circ} \mathrm{C}\right)$ and shoot xylem $\left(\mathrm{T}_{50}\right.$ of $\left.-35.0^{\circ} \mathrm{C}\right)$. Thus, 'AC Haroblush' should be adapted to the cooler areas in southern Ontario, Canada, and the neighboring U.S. states near the Great Lakes basin where 'Goldcot' is successfully grown.

Based on tree performance, fruit quality, and winter hardiness evaluations, 'AC Haroblush', together with 'AC Harojoy' and 'AC Harostar', which are being introduced at the same time (Layne and Hunter, 2003a, 2003b), will provide growers with additional opportunities for supplying the mid-season apricot market.

\section{Availability}

In testing carried out at the Canadian Food Inspection Agency's Centre for Plant Health, Sidney, B.C. (CPH-Sidney), 'AC Haroblush' was found to be free of all known viruses, virus-like agents, viroids, and phytoplasmas using an internationally approved range of woody and herbaceous host biological indicators, and by serological and molecular

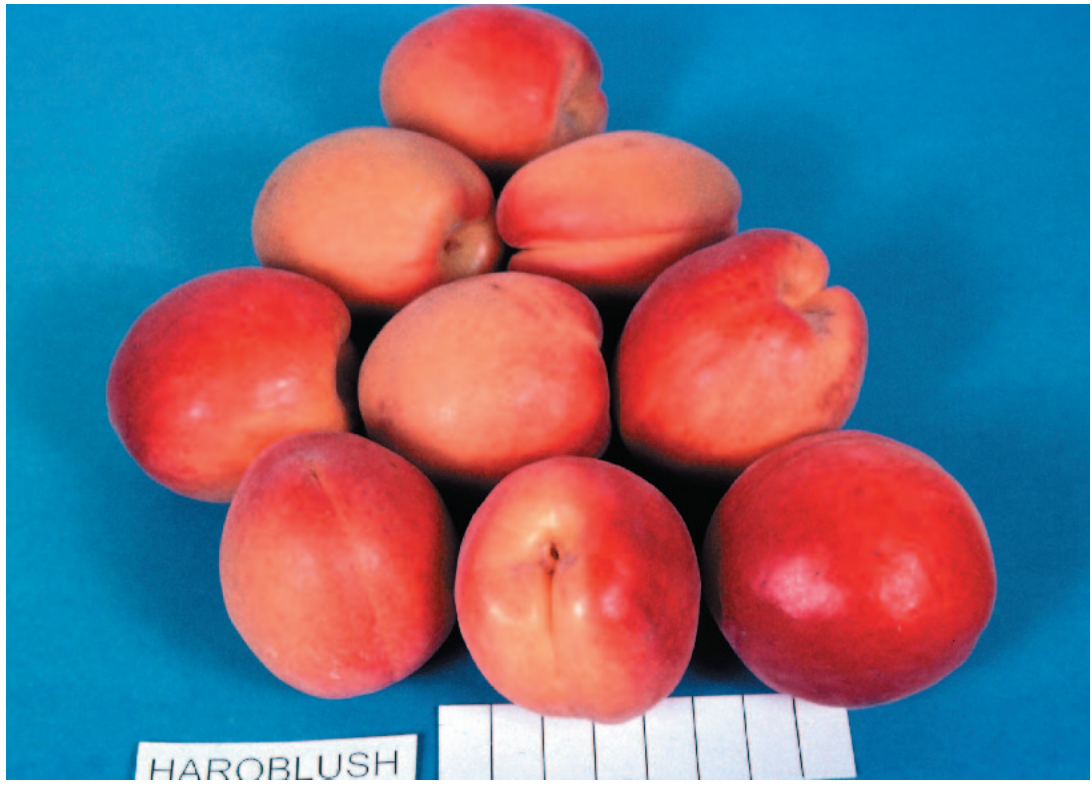

Fig. 2. Fruits of ‘AC Haroblush' apricot (scale in centimeters).

Table 1. Long-term performance of 'AC Haroblush' at Harrow, Ontario, Canada, compared with Veecot, AC Harostar, and Harogem (1988-95). ${ }^{\mathrm{z}}$

\begin{tabular}{|c|c|c|c|c|}
\hline \multirow[b]{2}{*}{ Characteristics evaluated } & \multicolumn{4}{|c|}{ Mean cultivar rating ${ }^{y}$} \\
\hline & Veecot & AC Haroblush & AC Harostar & Harogem \\
\hline Tree vigor & 8 & 8 & 7 & 8 \\
\hline Winter hardiness & 7 & 10 & 9 & 8 \\
\hline Perennial canker & 8 & 10 & 9 & 8 \\
\hline Bacterial leaf spot & 9 & 9 & 9 & 9 \\
\hline Bacterial fruit spot & 8 & 9 & 7 & 7 \\
\hline Productivity & 5 & 6 & 5 & 6 \\
\hline Ripening uniformity & 6 & 7 & 7 & 6 \\
\hline Fruit size & 6 & 7 & 7 & 7 \\
\hline Attractiveness & 7 & 7 & 7 & 8 \\
\hline Blush & 1 & 5 & 4 & 5 \\
\hline Flesh firmness & 8 & 7 & 8 & 8 \\
\hline Flesh adherence to pit & 10 & 10 & 8 & 9 \\
\hline Flavor & 6 & 7 & 7 & 7 \\
\hline Total score & 89 & 102 & 94 & 96 \\
\hline Mean ripe date & 21 July & 22 July & 23 July & 25 July \\
\hline
\end{tabular}

${ }^{\text {2} R a t i n g s ~ w e r e ~ s u b j e c t i v e ~ o n ~ a ~ s c a l e ~ o f ~} 1$ (least desirable) to 10 (most desirable). Ratings of 1 to 4 except for blush are considered unacceptable for a commercial cultivar; ratings of 5 and 6 are commercially acceptable; while ratings $\geq 7$ indicate a good to excellent level of performance.

${ }^{\mathrm{y}}$ Means for three single-tree replicates planted in a completely random design.

methods (D. Thompson, personal communication). Trees propagated from virus-free budwood have been planted in the Canadian Clonal Gene Bank at AAFC-Harrow. In annual monitoring at AAFC-Harrow, these budwood trees have been tested free of prunus necrotic ringspot virus, prune dwarf virus, and tomato ringspot virus using herbaceous (cucumber) and woody ('Shirofugen' cherry) indicators. Limited quantities of virus-tested budwood are available from AAFC-Harrow and $\mathrm{CPH}-$ Sidney. Testing of 'AC Haroblush' is subject to signing a non-propagation testing agreement with AAFC-Harrow. Information on commercialization licenses in Canada and the United States can be obtained by contacting the Director, Agriculture and Agri-Food Canada, Greenhouse and Processing Crops Research Centre, Harrow, Ontario NOR 1G0, Canada. 'AC Haroblush' has been protected in the European Union on behalf of Agriculture and Agri-Food Canada by Star Fruits, Route
d'Orange, 84860 Caderousse, France, to whom inquiries for commercial propagation of 'AC Haroblush' in the European Union should be directed.

\section{Literature Cited}

Layne, R.E.C. 1978. 'Harcot' apricot. HortScience 13:64-65.

Layne, R.E.C. 1984. 'Harglow' apricot. HortScience 19:136-137.

Layne, R.E.C. and M.F. Gadsby. 1995. Determination of cold hardiness and estimation of potential breeding value of apricot germplasm. Fruit Var. J. 49:242-248.

Layne, R.E.C. and T.B. Harrison. 1975. 'Haggith' apricot: Rootstock seed source. HortScience 10:428.

Layne, R.E.C. and D.M. Hunter. 2003a. 'ACHarojoy' apricot. HortScience 38:138-139.

Layne, R.E.C. and D.M. Hunter. 2003b. 'AC Harostar' apricot. HortScience 38:140-141. 